\title{
A Influência de Ambientes de Uso Adversos na Coleta de Dados Estatísticos Utilizando Dispositivos Móveis
}

\author{
Patricia Z. Tavares ${ }^{1,2}$, Simone B. Leal Ferreira ${ }^{2}$, Luiz Agner ${ }^{1}$, Eliane P. Capra ${ }^{2}$ \\ ${ }^{1}$ IBGE - Instituto Brasileiro de Geografia e Estatística \\ Rio de Janeiro - RJ - Brasil \\ ${ }^{2}$ UNIRIO - Departamento de Informática Aplicada \\ Rio de Janeiro - RJ - Brasil \\ \{pztavares, luizagner\}@gmail.com, \{simone, eliane.capra\}@uniriotec.br
}

\begin{abstract}
This paper aims to propose recommendations to facilitate the electronic statistical data collection in personal interviews. In this method, known as CAPI (Computer Assisted Personal Interviewing), the interviewer conducts the interview assisted by a handheld computer. To develop the recommendations, researchers made observations in fieldworks, usability tests on mobile laboratory, photographs and testimonials from the interviewers. Thus, it is expected to do interviews with more quality, in order to improve data input, help in reading the questions for the informants, maximize the data quality and integrity and reduce the training costs.
\end{abstract}

Resumo. O presente artigo tem como objetivo propor recomendações para facilitar a coleta eletrônica de dados estatísticos em entrevistas pessoais utilizando dispositivos móveis. Neste método, conhecido como CAPI (Computer-Assisted Personal Interviewing), o entrevistador se aproxima do informante e realiza a entrevista com o apoio de um computador de mão. Para elaborar tais recomendações, foram realizadas observações em acompanhamentos de campo, testes de usabilidade em laboratório portátil, registros com fotos, além de depoimentos dos entrevistadores. Com isso, espera-se tornar a entrevista mais eficiente, de forma a agilizar a entrada dos dados, ajudar na leitura das perguntas para melhor entendimento dos informantes, maximizar a qualidade e a integridade dos dados coletados $e$ reduzir custos com treinamentos.

\section{Introdução}

A evolução da tecnologia da comunicação sem fio e dos dispositivos móveis permitiu que os questionários confeccionados em papel fossem substituídos por questionários eletrônicos nas coletas de dados para pesquisas. Os benefícios da tecnologia, somados à mobilidade, permitiram que a coleta de dados seja realizada a qualquer hora e em qualquer lugar, possibilitando a melhora do desempenho e a qualidade dos dados coletados [Gravlee et al. 2006].

No método CAPI (Computer-Assisted Personal Interviewing), o entrevistador se aproxima do informante e realiza a entrevista com o apoio de um computador de mão. Sua tarefa é manter a atenção nas respostas do informante e inserir os dados 
corretamente no computador [Lepkowski et al. 1998]. Sendo assim, no método CAPI, o entrevistador é o usuário do sistema da coleta eletrônica de dados.

Porém, existem razões que tornam críticas as entrevistas apoiadas por computadores em uma pesquisa de grandes proporções, tais como: entrevistadores com perfis diferentes, além da diversidade de suas habilidades em informática; variedade de locais de trabalho e de informantes; pouco treinamento no uso do computador e falta de um suporte imediato de uma equipe técnica [Couper \& Nicholls 1998] [Lepkowski et al. 1998].

Somando-se a esses fatores, os dispositivos móveis, apesar de sua versatilidade, têm limitações físicas [Nielsen \& Budiu 2012] como telas e teclados reduzidos. Além disso, a navegação intuitiva e a identificação do conteúdo são consideradas necessidades absolutas em aplicações nesses dispositivos.

Eventuais problemas de interface podem dificultar a coleta dos dados e afetar negativamente a interação entrevistador-informante, podendo comprometer os resultados [Gravlee et al. 2006]. O entrevistador tem o potencial de impactar no processo de coleta de dados [Jäckle et al. 2013], pois a qualidade dos dados é dependente de sua capacidade de trabalho. Portanto, suas necessidades devem ser consideradas com alta prioridade e os sistemas devem ser flexíveis para lidar com uma variedade de procedimentos e situações da pesquisa [Jäckle et al. 2013]. Dessa forma, é fundamental que eles manipulem um instrumento de coleta de dados que seja fácil de usar e de aprender, sendo eficiente para completar a tarefa com sucesso e minimizando o número de erros cometidos [Couper \& Nicholls 1998].

O Instituto Brasileiro de Geografia e Estatística (IBGE) vem investindo em mobilidade nas coletas de dados estatísticos de suas pesquisas [IBGE 2010]. Motivada por este crescimento do uso de computadores de mão nas pesquisas de coletas de dados, a presente pesquisa busca identificar algumas dificuldades de uso enfrentadas pelos entrevistadores durante a realização de entrevistas pessoais que empregam computadores móveis nas pesquisas estatísticas domiciliares. A finalidade é propor recomendações para orientar o desenvolvimento de sistemas de coleta de dados utilizados em PDAs (Personal Digital Assistants), para permitir que os dados sejam coletados com maior agilidade e qualidade.

Para isso, foram realizadas observações nas entrevistas em campo (ambiente de uso) e testes de usabilidade em laboratório portátil com a participação de entrevistadores do IBGE durante a coleta de dados de duas de suas grandes pesquisas: o Censo 2010 e a PNAD Contínua.

\subsection{Estrutura do Artigo}

O artigo está dividido em nove seções, incluindo esta seção de introdução:

A seção 2 (CAPI - Entrevista Pessoal Assistida por Computador) aborda a revisão da literatura de alguns métodos de coleta de dados, enfatizando o método CAPI (Computer-Assisted Personal Interviewing), que é o foco deste artigo. A seção também expõe o histórico do uso de dispositivos móveis no IBGE ao coletar os dados de suas pesquisas domiciliares pelo método CAPI. 
A seção 3 (Avaliação de Usabilidade do Instrumento de Coleta) enumera as questões de usabilidade envolvidas no momento em que um entrevistador utiliza um dispositivo móvel para realizar uma entrevista pessoal.

A seção 4 (Trabalhos Anteriores) cita alguns trabalhos realizados que contribuíram para a delimitação dos objetivos deste artigo.

A seção 5 (Método de Pesquisa) apresenta as estratégias que foram empregadas para o processo de pesquisa.

A seção 6 (Observações no Contexto de Uso) expõe as observações dos pesquisadores ao acompanhar os entrevistadores do IBGE a cinco localidades diferentes. $\mathrm{O}$ objetivo foi entender as reais condições de trabalho dos entrevistadores e suas facilidades e dificuldades ao utilizar equipamentos móveis para realizar as entrevistas pessoais.

A seção 7 (Testes de Usabilidade em Laboratório Portátil) descreve o passo a passo das sessões dos testes de usabilidades aplicados com o auxílio de um laboratório portátil.

A seção 8 (Recomendações de Usabilidade para PDAs Utilizados em Entrevistas Pessoais para Pesquisas Domiciliares) mostra recomendações de usabilidade geradas pela análise das seções 6 e 7, para tornar mais eficiente a entrada dos dados nas coletas utilizando dispositivos móveis.

A seção 9 (Considerações Finais) apresenta as conclusões do estudo.

\section{CAPI - Entrevista Pessoal Assistida por Computador}

A evolução dos computadores permitiu que as coletas de dados para pesquisas, que antes eram realizadas com o apoio de questionários dispostos em formulários de papel (método conhecido como PAPI - Paper-And-Pencil Interviewing), fossem substituídos por questionários eletrônicos disponibilizados em computadores. As primeiras versões digitais funcionavam em mainframes, onde os entrevistadores manipulavam os terminais e realizavam contatos telefônicos para entrevistar os informantes, método que ficou conhecido como CATI (Computer-Assisted Telephone Interviewing) [Couper \& Nicholls 1998].

O avanço dos computadores pessoais e da tecnologia da comunicação sem fio, além da crescente utilização de equipamentos móveis, permitiram mais uma alternativa para a coleta de dados: a entrevista pessoal apoiada por computadores (CAPI Computer-Assisted Personal Interviewing). Nesse tipo de coleta, as vantagens da tecnologia são aliadas à mobilidade necessária para coletar os dados, permitindo que o entrevistador se aproxime do informante com um computador portátil ou um computador de mão (smartphone, PDA, tablet) para entrevistá-lo pessoalmente a qualquer hora, em qualquer lugar [Gravlee et al. 2006]. Porém, a qualidade dos resultados é influenciada pelo ambiente de uso e pela boa interação entre o entrevistador e o informante, e entre o entrevistador e o computador [Childs \& Landreth 2006].

No momento da entrevista é o entrevistador que manipula o computador. Sua tarefa é gerenciar duas interações simultaneamente (com o computador e com o informante), ou seja, manter a atenção nas respostas do informante e manter o foco na 
tarefa de inserir os dados corretamente no computador [Lepkowski et al. 1998]. Por isso, o entrevistador é considerado o elemento mais importante numa entrevista, pois ele é a principal ligação com a fonte dos dados, o informante [Jäckle et al. 2013]. O entrevistador precisa manter uma boa interação com o informante [Childs \& Landreth 2006], pois é nessa interação que ele consegue o seu objetivo: a coleta dos dados.

Como o informante é ponto de referência em uma entrevista [Lepkowski et al. 1998], ao abordá-lo o entrevistador deve procurar criar um vínculo de confiança. Como recusas ocorrem principalmente no início da entrevista, a sensibilidade e a agilidade do entrevistador para começar a entrevista são fundamentais [Jäckle et al. 2013] [Loosveldt \& Beullens 2013].

A automação da coleta de dados facilita o trabalho do entrevistador, melhorando o seu desempenho e maximizando a qualidade dos dados coletados. Entretanto, telas mal elaboradas podem atrapalhar e atrasar a coleta dos dados e podem comprometer os resultados [Gravlee et al. 2006].

A facilidade de uso do software de coleta de dados é determinada, em grande parte, pelo projeto da interface, como exibição de informações, disponibilidade, aplicação de recursos do sistema e o feedback fornecido após as ações do entrevistador. Os projetistas de sistemas de coleta de dados tendem a negligenciar o impacto da tecnologia nos entrevistadores, focando principalmente na viabilidade (programação, tecnologia e custos) e na funcionalidade (garantir que o sistema funcionou conforme planejado), preocupando-se pouco com a usabilidade [Couper, 1994] [Hanses, Couper \& Fuchs 1998].

\subsection{O Uso de Dispositivos Móveis nas Coletas de Dados do Instituto Brasileiro de Geografia e Estatística (IBGE)}

Desde o Censo 2000 o Instituto Brasileiro de Geografia e Estatística (IBGE) investe em computadores de mão. A partir de 2001, outras pesquisas domiciliares começaram a utilizar esta tecnologia para fazer sua coleta de dados, como a Pesquisa Mensal de Empregos (PME) e a Pesquisa Nacional por Amostra de Domicílios (PNAD). Em 2007, esses equipamentos foram largamente utilizados na Contagem da População e no Censo Agropecuário [IBGE 2010].

Para os testes do Censo 2010, o IBGE avaliou a possibilidade de adotar netbooks para as pesquisas. Mas os entrevistadores reclamaram do equipamento, pois, como geralmente a pesquisa é realizada em pé, com o tempo ele passa a ter dores no braço, além do maior consumo de bateria e risco de roubo. Após os testes, o PDA foi considerado ideal para a coleta de dados do Instituto [IBGE 2010].

\section{Avaliação de Usabilidade do Instrumento de Coleta}

O desempenho da entrevista e a confiabilidade dos dados dependem da facilidade do uso do dispositivo de coleta [Hanses, Couper \& Fuchs 1998]. À medida que o instrumento automatizado facilita o desempenho do entrevistador e sua interação com o informante, melhorias na qualidade dos dados vão surgindo [Lepkowski et al. 1998]. Logo, é importante que se dê importância aos requisitos de usabilidade para o uso do dispositivo. A avaliação da usabilidade aborda o projeto do instrumento de coleta, sua 
funcionalidade e seus requisitos de usabilidade, permitindo identificar pontos em que os entrevistadores têm dificuldade de interagir com o computador.

Algumas razões tornam essa avaliação crítica: (a) o grande número de entrevistadores e a diversidade de suas habilidades em informática; (b) variedade de locais de trabalho e de informantes; (c) pouco tempo para o treinamento no uso do computador (hardware e software); (d) alguns entrevistadores trabalham sozinhos, portanto eles dependem de seus conhecimentos e têm pouca ajuda em campo. Como o entrevistador tem o potencial de impactar no processo de coleta de dados, a concepção de sistemas para maximizar sua eficiência e minimizar os erros é essencial [Jäckle et al. 2013].

Normalmente, o usuário móvel interage com o equipamento ao mesmo tempo em que pode estar realizando outras tarefas. Além disso, os acontecimentos de um ambiente externo são imprevisíveis, que podem distrair o usuário. Sendo assim, o usuário de dispositivos móveis se distrai e se desconcentra com mais facilidade que o usuário de computadores em ambientes fixos. Portanto, a interface de um dispositivo móvel deve exigir o menor nível possível de concentração do usuário [Nielsen \& Budiu 2012].

Diante dessas complexidades, é importante envolver o usuário durante a avaliação das interfaces do instrumento de coleta, uma vez que o processo de produção de softwares depende do fator humano. Ao envolver o usuário na avaliação das interfaces, é possível entender melhor como ele elabora o seu modelo mental a respeito do sistema computacional [Leal Ferreira \& Nunes 2008].

Como a qualidade dos dados é influenciada pelo ambiente de uso e pela boa interação entre o entrevistador e o informante, as avaliações de usabilidade com a participação do usuário, no caso, o entrevistador, devem ser realizadas no contexto de uso do dispositivo; nesse caso, a avaliação ocorre nos locais de trabalho do entrevistador (no momento em que ele está entrevistando o informante). Essas observações permitem que o pesquisador acompanhe os participantes em um ambiente familiar e a interação acontece com as configurações de hardware e software usuais [Nielsen \& Budiu 2012].

\section{Trabalhos Anteriores}

Foram identificadas na literatura algumas pesquisas que serviram de informação para o trabalho do presente artigo:

- Heurísticas para a Coleta Eletrônica de Dados [Couper, 1994]: o autor aplicou os princípios de IHC nas coletas de dados apoiadas por computadores e propôs dez heurísticas: funcionalidade, consistência, feedback informativo, transparência, clareza, compreensibilidade, tolerância, eficiência, suporte e complexidade otimizada.

- Implementação de Computadores de Mão em Coletas de Dados [Gravlee et al. 2006]: este estudo descreve uma experiência de implementação de computadores de mão em trabalhos de campo, levando à conclusão que esses dispositivos são uma alternativa viável aos formulários de papel nas coletas de dados. 
- Interação entre o Entrevistador e o Informante [Childs \& Landreth 2006]: esse estudo teve como objetivo verificar como entrevistadores lêem as perguntas nas entrevistas pessoais e como os informantes interpretam essas perguntas, além de investigar se a automação do instrumento de coleta incentivava o processo.

- Guia para Questionários em Modos Mistos de Coleta de Dados [Martin et al. 2007]: o objetivo do trabalho foi compreender melhor e minimizar os efeitos decorrentes da utilização de múltiplos modos de coleta de dados (por telefone, email ou entrevista pessoal) em suas pesquisas com questionários em papel ou eletrônicos.

Os trabalhos relacionados nessa seção abordaram algumas experiências com coletas de dados utilizando dispositivos móveis: a implementação da tecnologia na coleta de dados [Gravlee et al. 2006], a utilização da usabilidade para melhorar a qualidade da coleta dos dados [Couper, 1994], a importância do estudo da experiência do usuário nos trabalhos de campo [Fox 2001] e os cuidados na elaboração do instrumento de coleta eletrônica [Childs \& Landreth 2006] [Martin et al. 2007].

Tais trabalhos contribuíram para o reconhecimento dos desafios enfrentados pelos entrevistadores nas entrevistas de campo, facilitando a delimitação do problema de pesquisa. Os trabalhos enfatizam os efeitos da facilidade do uso do instrumento de coleta nos resultados das pesquisas. Como a qualidade dos dados depende desse instrumento, o foco desse trabalho foi avaliar como o instrumento de coleta pode facilitar o trabalho dos entrevistadores em entrevistas pessoais utilizando um dispositivo móvel e propor recomendações que permitam que os dados sejam coletados com agilidade e qualidade, análise não abordada nos trabalhos anteriores.

\section{Método de Pesquisa}

A pesquisa, de caráter qualitativo e exploratório, teve seis etapas:

(a) Observações no contexto de uso: com o objetivo de conhecer o usuário, seu comportamento ao utilizar o PDA e o ambiente de uso desse equipamento, os pesquisadores acompanharam equipes do IBGE em cinco entrevistas apoiadas pelo dispositivo móvel. Como as entrevistas são realizadas por milhares de pessoas de variadas localizações geográficas, as observações foram realizadas em visitas a locais com características diferentes, a fim de conhecer as diversas condições de trabalho em que o dispositivo móvel é utilizado.

A abordagem aos informantes e como eles reagiam também foram observados, para perceber os pontos negativos do instrumento informatizado e estudar uma maneira de facilitar esta interação. Como o Instituto possui diversas pesquisas domiciliares que utilizam o PDA, foram selecionadas as seguintes para o acompanhamento de campo: a Pesquisa Nacional por Amostra de Domicílios Contínua (PNAD Contínua) e o Censo Demográfico. Após a definição das pesquisas, foram agendadas visitas a uma área nobre, a uma área urbana e a uma área rural do Rio de Janeiro. Num segundo momento, foram realizadas visitas a outra área nobre e uma comunidade de outra cidade, Belo Horizonte. 
(b) Gravações em vídeo da interação do entrevistador com o PDA na hora da entrevista: muitas vezes os entrevistadores enfrentavam problemas de interação ao manipular o PDA na hora em que iam entrevistar os informantes. Os pesquisadores não tinham a visão da tela do equipamento, somente o entrevistador conseguia ver a tela, pois o PDA estava em suas mãos e direcionado para ele. Então, os pesquisadores decidiram filmar as entrevistas, com o cuidado de considerar as limitações de uso das gravações, pois alguns informantes podem não se sentir à vontade ao serem filmados ou fotografados [Childs \& Landreth 2006]. Para evitar tais constrangimentos, os pesquisadores optaram por gravar somente a tela do PDA, mantendo a privacidade da entrevistadora e do informante. Para isso, foi construído um artefato projetado com uma extremidade para encaixar no case protetor do PDA e portar uma webcam sem fio em sua outra extremidade (Figura 1).

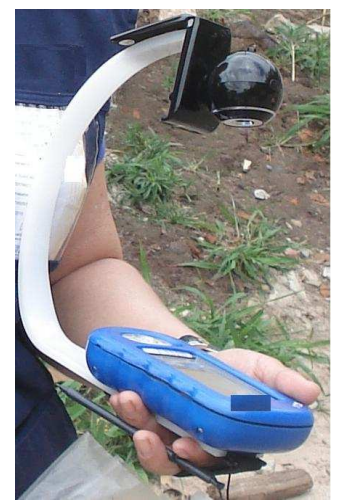

Figura 1. Artefato acoplado ao PDA com webcam.

O artefato acoplado ao PDA foi utilizado no quarto acompanhamento de campo, pois os pesquisadores ficaram aguardando uma oportunidade para usá-lo. Procurou-se não utilizar o artefato nas primeiras entrevistas, pois era interessante antes obter a confiança da usuária e observar como ela realizava seu trabalho de campo. Após acompanhar algumas entrevistas, foi decidido gravar a entrevista seguinte.

Portanto, esta etapa procurou explorar as reais características do contexto de uso do dispositivo móvel. A intenção foi captar a "visão do usuário" em uma situação de contexto real de uso, ou seja, o que o usuário está observando na tela do equipamento durante o seu trabalho de campo, como ele conduz o processo de acordo com o que lhe é mostrado na tela e o quanto as interferências do ambiente prejudicam o resultado da interação.

(c) Entrevistas não-estruturadas com os usuários: essa etapa foi conduzida pelos pesquisadores que acompanharam as visitas de campo, sendo realizada no mesmo dia das visitas, durante o percurso ou no final do dia. O objetivo foi aproveitar o momento oportuno, onde os acontecimentos recentes puderam ser discutidos com maior facilidade com os usuários, com seus relatos registrados em áudio e vídeo. Algumas gravações em vídeos foram realizadas em vários momentos durante o dia. Foram depoimentos rápidos, na rua, onde os usuários expressaram-se livremente focando em problemas específicos que foram observados. No último (quinto) acompanhamento de campo, a gravação do depoimento da usuária foi no final do dia, após o término dos trabalhos. O local escolhido foi uma lanchonete próxima ao local de visita, com a intenção de transformar o evento em um bate-papo informal e deixar a usuária mais à vontade. 
(d) Testes de usabilidade em laboratório: os testes tiveram como objetivo analisar o comportamento do usuário ao utilizar um dispositivo móvel, percebendo suas facilidades e dificuldades, além de coletar as suas sugestões e seus depoimentos sobre os trabalhos de campo;

(e) Análise dos Resultados obtidos na observação: Com a coleta e o registro de observações, foi gerado um grande número de informações que foram organizadas para serem interpretadas e reportadas.

(f) Elaboração das recomendações de usabilidade para coleta de dados utilizando PDAs em entrevistas pessoais para pesquisas domiciliares: a análise dos resultados contribuiu para a compilação de todos os dados recolhidos e as entrevistas em áudio e vídeo, o que possibilitou gerar uma lista de recomendações de usabilidade, a fim de difundir o PDA como um instrumento padrão para a coleta de dados domiciliares.

\subsection{Limitações do Método}

Apesar da área de abrangência nacional do IBGE, por questões de facilidade de acesso para os pesquisadores, as observações ficaram restritas as cidades do Rio de Janeiro e de Belo Horizonte.

Houve também uma resistência inicial por conta de alguns entrevistadores (usuários do PDA) para aceitar a participação nas observações, receosos que isto pudesse gerar mal-entendidos com os resultados. Mas, após algumas explicações e apresentações sobre os objetivos da pesquisa, os entrevistadores se interessaram em colaborar.

\subsection{Delimitação do Trabalho}

O presente estudo limitou-se a pesquisar a usabilidade para PDAs utilizados em entrevistas pessoais ao coletar dados para pesquisas domiciliares. Este estudo não se propôs a estudar sites ou outras aplicações desenvolvidas para PDAs. O equipamento direcionado para os trabalhos foi um PDA (Pocket PC Mio P550b). Não foram testados outros computadores de mão, como celulares, tablets ou smartphones.

O escopo foi limitado à entrevista pessoal (método CAPI), não abordando outros métodos de coleta de dados, como entrevistas por telefone (CATI), auto-entrevistas (CASI) ou coleta de dados pela Internet (CAWI).

\section{Observações no Contexto de Uso}

\subsection{Acompanhamento de Campo no ${ }^{1}$ : Área Nobre}

A primeira visita a campo, em março de 2010, contou com o apoio de uma equipe da PNAD Contínua, composta por um entrevistador e seu supervisor. O local escolhido foi o bairro do Leblon, área nobre da Zona Sul do Rio de Janeiro, com muitos edifícios residenciais de famílias de classe média alta.

Durante o trajeto, a equipe comentou que as áreas nobres são as que possuem maiores dificuldades de acesso aos entrevistadores. Muitas vezes o morador não está em casa ou oferece relutância para responder a pesquisa, pedindo ao porteiro para não permitir tal 
contato. O entrevistador ressaltou que os idosos são mais fáceis de entrevistar porque essas pessoas adoram conversar sobre sua vida e receber visitas.

Chegando ao local, o entrevistador procurou os domicílios que estavam na sua lista impressa para entrevistar os moradores. Após cerca de dez tentativas com negativas de acesso aos domicílios da lista, finalmente ele conseguiu entrar em uma residência.

Após se identificar, o entrevistador procurou ser cordial com a dona da casa e pediu a sua permissão para que os pesquisadores pudessem também acompanhar a entrevista. Ela concordou sem nenhuma resistência.

A moradora conduziu o entrevistador e os pesquisadores até a varanda. $\mathrm{O}$ entrevistador sentou-se no local indicado pela informante, mas logo pediu para trocar de lugar devido à luminosidade que incidia sobre o seu PDA, dificultando a sua operação.

$\mathrm{O}$ entrevistador começou a entrevista. Algumas vezes o entrevistador adaptou algumas perguntas que eram apresentadas na tela do PDA, pois eram grandes e exaustivas. A entrevistada passou a conversar em tom informal com o entrevistador, detalhando melhor o que estava sendo perguntado. Isso gerou a necessidade de uma boa interpretação por parte do entrevistador.

Estruturas e frases complexas no questionário são alguns dos elementos que podem interferir na compreensão das perguntas na hora da entrevista [Loosveldt \& Beullens 2013]. Uma pergunta mal compreendida pode levar a uma complexa interação entrevistador-informante, que pode levar a uma maior dificuldade para a interação entrevistador-computador [Lepkowski et al. 1998]. A entrevistada só se sentiu desconfortável quando precisou falar dos rendimentos familiares.

Em alguns casos, o entrevistador precisou de um tempo considerável entre as perguntas do questionário para operar o PDA. Durante esses intervalos, ficou calado e clicou diversas vezes na tela touchscreen do dispositivo com a sua caneta. A entrevistada mostrou-se um pouco entediada, esperando com educação a próxima pergunta. Reações adversas como comentários, risos, queixas ou silêncios prolongados podem revelar problemas de usabilidade e são indicadores de desconforto do entrevistador durante uma interação negativa com o computador [Childs \& Landreth 2006] [Jäckle et al. 2013].

Observou-se que, com a resposta de algumas perguntas, o entrevistador deduzia outras respostas de outras perguntas. Por exemplo, quando perguntou a entrevistada qual era seu grau de estudo, ela respondeu que ela já havia concluído o Mestrado. O entrevistador deduziu que ela sabia ler e escrever e, quando esta pergunta apareceu na tela do PDA, ele respondeu por ela sem perguntar.

Ficou demonstrada também a necessidade de cultura geral do entrevistador para a correta interpretação de algumas respostas e a capacidade de fazer cálculos financeiros de cabeça. A pressão de realizar a tarefa corretamente pelo entrevistador muitas vezes é confrontada com a necessidade de parar seu trabalho para usar sua memória. Neste caso, os recursos do computador para efetuar os cálculos devem ser facilmente acessados de forma a serem bem aproveitados, para reduzir o tempo de conclusão da entrevista e evitar a sobrecarga de memória do entrevistador [Childs \& Landreth 2006] [Martin et al. 2007]. 
Outro fato constatado foi o tempo consideravelmente alto para acessar uma pergunta anterior já respondida, caso o entrevistador precisasse conferir algum dado já inserido no PDA. Durante a entrevista, o uso do tempo do informante deve ser respeitado e uma entrevista muito longa implica no risco do informante interromper o processo e se recusar a continuar a entrevista; qualquer descuido neste momento pode ser irreversível no processo de entrevista [Jäckle et al. 2013].

A entrevista durou aproximadamente uma hora, tempo considerado normal pelo entrevistador, já que a moradora respondeu por três pessoas da casa. Ela disse que só deixou o entrevistador entrar em sua casa porque o IBGE tinha lhe enviado uma correspondência, informando que seu domicílio foi selecionado para responder a pesquisa e que o entrevistador iria procurá-la.

Ao deixar o domicílio, a pesquisadora perguntou ao entrevistador o motivo de ele adaptar as perguntas e não seguir o fluxo exato do questionário. Ele sabe que o fluxo do questionário deve ser seguido, mas alega que, se seguisse este fluxo, seria cansativo e estressante para o informante. Ele comentou que alguns informantes já ficaram chateados com algumas perguntas que freqüentemente causam polêmicas e discussões, como a pergunta sobre raça ou as perguntas sobre o rendimento dos moradores. Essa "tradução" das perguntas pode causar uma interpretação errada por parte do usuário ao adaptar a pergunta, afetar o seu significado e fazer com que ele obtenha uma resposta não coerente com a pergunta original [Martin et al. 2007].

\subsection{Acompanhamento de Campo no 2: Áreas Urbanas}

Em março de 2010, os pesquisadores acompanharam outra equipe da PNAD Contínua a alguns bairros do subúrbio carioca (Encantado, Piedade, Bonsucesso e Higienópolis). Os entrevistadores não possuem grandes problemas de acesso aos informantes para a realização das pesquisas.

Os pesquisadores acompanharam duas entrevistadoras. Junto com uma lista, com alguns domicílios para visitar em bairros diferentes, elas também possuíam um mapa impresso do local para sua localização. Elas comentaram que, por ser uma sexta feira, talvez não conseguissem realizar muitas entrevistas, uma vez que durante a semana é mais difícil para encontrar os moradores por estarem trabalhando ou ocupados com as tarefas domésticas. Elas disseram também que muitos idosos fazem até bolos e doces, ansiosos por suas visitas para contar suas histórias de vida.

Depois de algumas tentativas, elas conseguiram acessar uma informante, que se propôs a responder a pesquisa. A entrevistadora então ligou o seu PDA, localizou o domicílio na tela e começou as perguntas. Ela estava sob um sol forte e em pé, na porta da casa da informante. A casa da informante era em frente a uma serralheria e perto da linha do trem. Observou-se a dificuldade de visualização do questionário no PDA por causa da luz solar refletida na tela. $O$ barulho do trem e da serralheria fez com que a entrevista se estendesse, pois a entrevistadora não conseguia ouvir bem a entrevistada e vice-versa. A entrevista era freqüentemente interrompida pelos seis filhos da entrevistada, que estavam curiosos com o equipamento na mão da entrevistadora.

O uso do computador no momento da entrevista é completamente imprevisível: o entrevistador pode estar dentro de um ambiente fechado ou em um ambiente externo; pode estar de pé ou sentado; o local pode ser um ambiente silencioso ou com barulho 
[Nielsen \& Budiu 2012]. Caso o entrevistador se distraia com os acontecimentos ao seu redor e o sistema precisa fornecer feedbacks na tela para auxiliá-lo a se concentrar novamente no trabalho.

Após o término da entrevista, as entrevistadoras continuaram seguindo o roteiro. Conseguiram acesso a alguns moradores, mas eles educadamente pediam que elas voltassem em outro horário. Somente um deles foi indelicado, dizendo que ela deveria procurar seu advogado para fazer as perguntas, pois se recusava a respondê-las. A entrevistadora registrou essa recusa no PDA.

Ao fim do dia, as entrevistadoras disseram que foi um dia de semana típico de trabalho, mas, como moravam perto do local, tinham facilidade de retornar para efetuar mais tentativas de acessar os domicílios não entrevistados.

\subsection{Acompanhamento de Campo no 3: Área Rural}

Em agosto de 2010, foi observada uma entrevista da PNAD Contínua em uma área rural no Rio de Janeiro, coordenada pela agência de Itaboraí que concentra as coletas de alguns municípios vizinhos como Rio Bonito, Silva Jardim e Tanguá.

O coordenador da agência e alguns supervisores, pelo tempo de experiência com essas pesquisas, confirmaram as dificuldades de acesso a alguns domicílios situados em áreas nobres, pois já trabalharam nestes locais.

O coordenador comentou que não entende o porquê da diferença entre os aplicativos do IBGE desenvolvidos para PDA, já que as pesquisas são semelhantes. Declarou que às vezes é interessante realizar um rodízio entre os membros das equipes, mas os aplicativos não são padronizados, forçando-o a perder tempo com o treinamento de cada aplicativo. Ele fez comparações, enfocando as vantagens e desvantagens das funcionalidades de cada um deles. Como não existe um padrão de interfaces para o desenvolvimento dos aplicativos do Instituto, cada aplicação desenvolvida possui uma interface distinta. Isso acaba gerando sistemas com diferentes facilidades e funcionalidades, gerando inevitáveis comparações. Se as interfaces dos aplicativos fossem mais consistentes, seria possível generalizar o conhecimento obtido em um sistema para outros sistemas, para evitar que o entrevistador precisasse aprender tudo novamente [Leal Ferreira \& Nunes 2008].

Para os trabalhos de campo, o coordenador apresentou o entrevistador da área que seria visitada, em Tanguá, numa área rural. O entrevistador comentou da grande distância até encontrar o local e da dificuldade em se encontrar o ponto de referência.

Apesar de ser inverno, o sol estava muito forte. Se estivesse chovendo, não seria possível chegar ao setor, caso o veículo não fosse apropriado para o local. Para chegar ao local, além do entrevistador se basear no mapa impresso e da listagem dos domicílios, ele contava com anotações como placas, cartazes políticos, cor dos muros e plantas que possam caracterizar o local. A listagem dele tinha alguns endereços muito vagos, do tipo "Caminho sem nome, 1" ou "Estrada sem nome, S/N".

Após muitas voltas, o domicílio selecionado foi localizado; seu dono estava na varanda. $\mathrm{O}$ entrevistador se identificou e pediu licença para fazer a entrevista. Mesmo desconfiado, o dono da casa aceitou a abordagem. 
Antes de começar a entrevista, o entrevistador se posicionou na varanda da casa. Ligou o PDA e percebeu que ali não era um bom local, pois o sol iria atrapalhar a leitura das informações na tela, direcionando-se para a sombra.

O entrevistador começou a usar o PDA silenciosamente; o informante aguardava com paciência e ao mesmo tempo com curiosidade, esperando a primeira pergunta. Ele começou a perguntar e observou-se que ele seguiu a ordem correta das perguntas do questionário, que apareciam na tela do PDA. Durante a entrevista muitas vezes o entrevistador ficava calado manipulando o PDA e o informante ficava olhando e esperando a próxima pergunta. Apesar da paciência com que esperava, percebeu-se que a demora era monótona. A lentidão do computador ao apresentar as perguntas pode causar um efeito negativo durante a entrevista: o informante pode se recusar a começar ou continuar a entrevista [Jäckle et al. 2013].

Muitas perguntas deixavam o informante inibido, como ao falar sobre o seu baixo salário. Ele respondia com educação, mas em algumas ele não entendia o que lhe era perguntado. $\mathrm{O}$ entrevistador gastava muito tempo explicando essas perguntas várias vezes.

O entrevistador ficava sempre tentando ser cordial e solidário com o informante, explicando que o questionário já estava acabando. Observou-se que não tinha nada na tela do PDA que confirmava este fato, ele apenas se guiava pela numeração alta das questões, já decoradas por ele.

O entrevistador conseguiu ganhar a confiança do informante para obter todos os dados que precisava. No final, ele perguntou o motivo da pesquisa, o que foi prontamente explicado pelo entrevistador.

Após uns quinze minutos de carro, o outro domicílio da lista foi encontrado. O dono da casa aceitou responder, mas antes queria saber qual era a vantagem que ele iria ganhar com a pesquisa; ele também se mostrou preocupado com a possibilidade de perder algum benefício que ele já tinha ("Bolsa Família"). O entrevistador esclareceu a função social da pesquisa e do IBGE, mas ficou nítido que o homem não entendeu a explicação e continuou desconfiado.

O informante não teve resistência em dizer o telefone dele no início da entrevista. Segundo o entrevistador isto é um fato marcante, pois muitos informantes não gostam de dizer seu telefone logo no início da abordagem.

$\mathrm{O}$ entrevistador fez as perguntas seguindo a ordem que apareciam na tela do PDA e o homem respondia a todas com atenção. Ao digitar uma resposta de uma pergunta aberta, o entrevistador errou na digitação e rapidamente consertou utilizando o backspace e a inserção do teclado virtual. A entrevista transcorreu sem problemas e ficou dentro da média de tempo.

\subsection{Acompanhamento de Campo no 4: Área Nobre}

Em outubro de 2010, os pesquisadores acompanharam a abordagem do Censo $2010 \mathrm{em}$ Belo Horizonte. O local visitado foi o Sion, um bairro de classe média alta. Esta etapa contou com a colaboração de uma recenseadora. 
Ela descreveu o bairro como sendo um dos mais tradicionais e valorizados da cidade, com a população basicamente composta por pessoas de classe média alta e muitos idosos.

Chegando ao prédio, uma moradora idosa que tinha saído para caminhar chegou e aceitou ser entrevistada. Enquanto a recenseadora manipulava o PDA para iniciar a entrevista, a idosa contava a sua vida e seus problemas de saúde; percebeu-se a dificuldade da recenseadora ao tentar dividir a sua atenção com a idosa e com o PDA.

As perguntas do questionário eram apresentadas na tela do PDA, uma de cada vez. Para navegar entre as perguntas, a recenseadora clicava em dois botões, um para voltar para a pergunta anterior e outro para avançar para a próxima pergunta. Eles estavam muito próximos e eram pequenos, atrapalhando diversas vezes a recenseadora, pois ela errava muito ao clicar neles com pressa: isso a incomodou muito, pois estava perdendo tempo. Durante a entrevista, a recenseadora precisou fazer alguns cálculos mentalmente, como somar os vários aluguéis que uma moradora recebia para computar seu rendimento mensal.

O sistema tinha recursos interessantes, como a sugestão de palavras: à medida que o entrevistador ia digitando um texto, o sistema ia sugerindo palavras que eram compatíveis, minimizando o tempo de digitação e a quantidade de informação na tela reduzida do PDA.

A recenseadora fazia perguntas e a idosa respondia com dificuldade, nem sempre se lembrava dos fatos e a acompanhante dela ajudava em alguns casos. Nesses momentos a recenseadora perdeu muito tempo tendo que voltar às perguntas anteriores para realizar tais alterações, já que não havia possibilidade de acessar direto uma pergunta específica. Além disso, também não existia a possibilidade de mostrar a recenseadora as respostas que já foram inseridas de forma única.

Ao final da entrevista, o questionário solicitou a assinatura da informante. A recenseadora pediu para a idosa "assinar" no PDA. Então, a idosa pegou a caneta Stylus e escreveu com muita dificuldade na superfície do PDA. Ela não gostou do resultado, se desculpou e achou que a culpa era dela por não saber lidar bem com a tecnologia.

Em outra tentativa de entrevista, uma moradora aceitou a abordagem e, de dentro de sua residência, respondeu as perguntas, enquanto a recenseadora ficou em pé do lado de fora da casa. Como ela estava na sombra, não teve dificuldades para ler na tela do PDA.

Sempre que perguntada por algum morador, a recenseadora explicava a importância da pesquisa. Não foi observado se existia alguma opção no PDA que pudesse apoiar a recenseadora nestes casos, contendo informações sobre a pesquisa e os benefícios obtidos com seus resultados.

Nesta abordagem, alguns fatos marcantes devem ser ressaltados:

- Todos ficaram desconfortáveis ao falar sobre seus rendimentos. Para contornar a situação, a recenseadora mostrava a tela do PDA com as faixas de rendimento e pedia para o morador "encaixar" o seu rendimento nelas.

- Muitas perguntas geravam polêmicas e pequenos debates, como a pergunta sobre a raça dos moradores; 
- Notou-se que em geral a tecnologia foi bem aceita pelos informantes, já que a maioria gostou da oportunidade de "assinar" no PDA. Entretanto, outros tiveram dificuldades em manusear a caneta utilizada pelo equipamento.

- A recenseadora utilizava uma linguagem popular para formular e reduzir algumas perguntas, em vez de lê-las por completo, de forma a tornar a entrevista menos entediante e mais natural para o entrevistado;

- Em muitos casos a recenseadora invertia a ordem das questões propostas pelo software de questionário eletrônico, com o objetivo de reduzir a duração da entrevista e evitar perguntar coisas óbvias para o entrevistado;

- O clima da entrevista era conduzido pelo entrevistado, principalmente quando o contato era amistoso, o que contribuía para aumentar a confiança dos informantes na recenseadora;

- A recenseadora ficou em dúvida sobre alguns conceitos próprios da pesquisa, tentando lembrar o treinamento que teve há algum tempo atrás. Ficou evidente que a recenseadora dependia de sua memória e não foi observado se existia um botão de ajuda no aplicativo que pudesse conter a descrição de tais conceitos;

- Durante as entrevistas, muitos informantes demonstraram conhecer os objetivos do IBGE.

Apesar da previsão inicial da recenseadora dizendo que o dia ia ser difícil, no final do dia foram realizadas entrevistas em quinze domicílios, dentro de sua média diária.

\subsection{Acompanhamento de Campo no 5: Uma Comunidade}

Em outubro de 2010, os pesquisadores encontraram-se novamente com a recenseadora para acompanhar os trabalhos do Censo em Belo Horizonte, numa comunidade no bairro do Sion. Essa comunidade foi descrita pela recenseadora como um local onde moram muitas pessoas que trabalham nas redondezas como porteiros, diaristas, frentistas, entre outras ocupações.

Após 15 minutos de tentativa de localizar os domicílios e uma recusa, a recenseadora conseguiu contatar uma moradora, que aceitou a abordagem. No domicílio habitavam várias pessoas, o que fez demorar o trabalho de cadastro no PDA, pois a recenseadora tinha que perguntar os dados pessoais de cada morador. Além disso, a quantidade de pessoas envolvidas no momento às vezes desorientava a recenseadora, pois todos falavam ao mesmo tempo e ela tinha que se concentrar no PDA. Para evitar que a entrevista ficasse dispersa, ela narrava o que estava fazendo no PDA e pedia para que os moradores tivessem um pouco de paciência.

Em geral, os informantes reagem positivamente ao uso do computador durante uma entrevista; eles atribuem um maior grau de profissionalismo à pesquisa [Gravlee $e t$ al. 2006], pois a tecnologia pode transformar o contexto da entrevista e contribuir para a sensação de que é um evento importante. Em alguns casos, a curiosidade sobre a tecnologia chama mais pessoas para observar ou participar das entrevistas. Às vezes isso ajuda a "quebrar o gelo", ficando mais fácil falar com outros membros de uma família ou da comunidade. 
Na terceira casa a ser visitada, a infra-estrutura era precária. A moradora era jovem, frentista, e disse que tinha três filhos. Como estava muita claridade, a recenseadora foi forçada a proteger o PDA com sua própria sombra para poder utilizálo. Durante toda a entrevista, o cachorro da família ficou latindo e os dois filhos menores dela ficaram querendo brincar com o PDA. Isso desconcentrou a recenseadora, que precisava manter seu foco nas respostas da dona da casa e na manipulação correta do equipamento. Com o uso de dispositivos móveis em coletas dos dados, a usabilidade torna-se essencial devido à influência do contexto de uso, pois o ambiente móvel tende a distrair em função de outras atividades que ocorrem ao mesmo tempo no local [Nielsen \& Budiu 2012].

Após a entrevista na comunidade, a recenseadora chegou a um prédio e começou a tocar os interfones, mas ninguém apareceu. Logo depois, um morador chegou de carro e entrou na garagem. Ela o abordou pelo portão e ele se propôs a responder, mas demonstrava muita pressa. Ele perguntou a quantidade de perguntas e se ia demorar muito, e a recenseadora disse que seriam "só cinco minutinhos". A pergunta "Quanto tempo vai demorar a entrevista?" é freqüentemente indagada pelos informantes quando o entrevistador realiza a abordagem inicial [Loosveldt \& Beullens 2013].

O homem ficou de pé, impaciente, do lado de dentro da portaria do prédio, enquanto a recenseadora ficou de lado de fora. Como o Censo tinha dois questionários (um básico, menor e outro da amostra, bem maior), a recenseadora comentou que ficou apreensiva porque o PDA poderia apresentar o questionário da amostra, o que demoraria mais de cinco minutos. A cada ação do usuário, ou sempre que necessário, o sistema deve informar continuamente o que está acontecendo [Leal Ferreira \& Nunes 2008] e não foi observada no PDA uma indicação dizendo se o questionário apresentado seria o básico ou o da amostra.

\section{Testes de Usabilidade em Laboratório Portátil}

Paralelamente ao processo de observação do dia-a-dia dos usuários nas coletas de dados utilizando o PDA, foram realizados testes de usabilidade em laboratório para analisar o comportamento do usuário ao utilizar o dispositivo móvel em um ambiente semicontrolado, percebendo suas facilidades e dificuldades, além de coletar as suas sugestões.

\subsection{Início do Processo}

Procurou-se entender os conceitos de abordagem ao informante pelo IBGE para construir cenários de uso, que são textos com situações comuns que ocorrem nos trabalhos de campo, redigidos utilizando o vocabulário do usuário.

\subsection{Seleção da Amostra de Participantes}

Para analisar o perfil dos entrevistadores do IBGE, que são os usuários do PDA, foi elaborado um questionário online, contendo questões sobre o perfil do usuário, sua experiência com tecnologia e com outras pesquisas do IBGE.

Cada entrevistador foi convidado a responder o questionário e sinalizar se gostaria de participar dos testes de usabilidade. A intenção foi selecionar uma amostra 
de seis participantes, baseada nas recomendações propostas por Jakob Nielsen [Nielsen 2005].

\subsection{Sessões de Testes de Usabilidade}

Como não havia uma sala dedicada para os testes, foi utilizado um laboratório de usabilidade portátil [Rubin \& Chrisnell 2008], composto por um notebook equipado com software para captura de telas (Camtasia Studio 6), webcam, microfone e Windows Mobile Device Center (Figura 2).

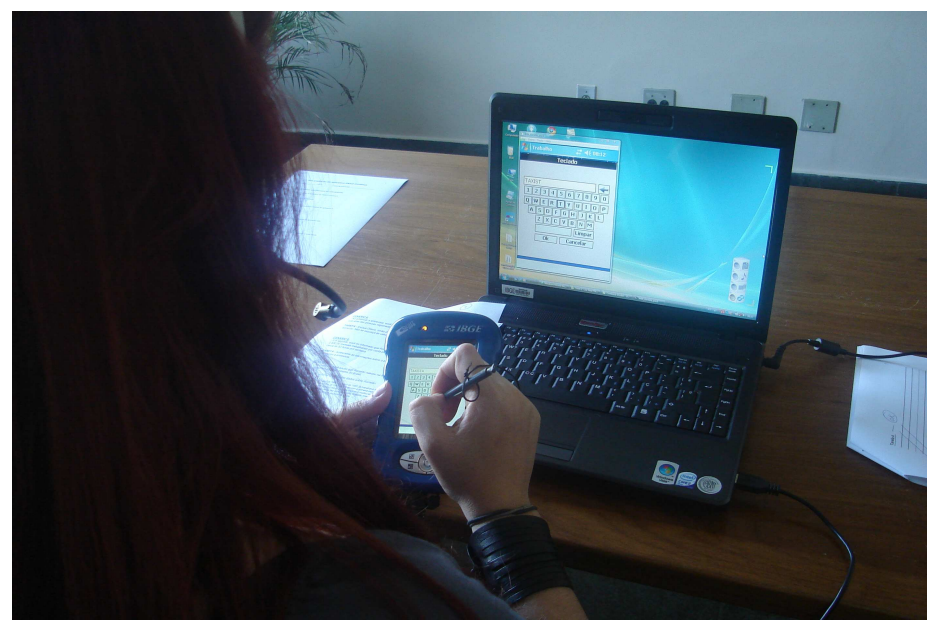

Figura 2. Laboratório portátil de usabilidade.

Cada uma das sessões foi conduzida da mesma maneira. Antes da chegada do participante, os pesquisadores escolhiam uma sala apropriada, arrumavam-na, ligavam e testavam os equipamentos. O PDA era sincronizado com o notebook.

$\mathrm{Na}$ chegada do participante, os pesquisadores apresentavam o objetivo da pesquisa e explicavam os procedimentos. Como exemplo, um vídeo gravado era mostrado.

Esclarecido o método, solicitava-se ao participante a assinatura de um termo de autorização para a gravação. Para evitar constrangimentos, foi enfatizado que o foco da avaliação estava em suas interações com o PDA e não em avaliar a performance do próprio participante.

Após a assinatura do termo, era aplicado um questionário de pré-teste com dez perguntas fechadas para identificar o perfil do participante. Respondido o questionário, eram iniciados os preparativos para as observações, propondo-se uma tarefa a cada vez ao participante.

Enquanto trabalhavam nas tarefas, os participantes foram incentivados a exteriorizar seus pensamentos em voz alta (think aloud protocol) [Rubin \& Chrisnell 2008]. Para captar tais discursos, foi fornecido ao participante um headphone com um microfone acoplado.

Como o PDA estava sincronizado com o notebook, uma simulação da tela do PDA aparecia na tela do notebook. Portanto, todo movimento que o participante 
realizava no PDA era reproduzido na tela do notebook. A webcam, por sua vez, mostrava as reações do usuário. Todo o processo de avaliação de usabilidade era registrado através de gravações em vídeo e áudio.

O software de gravação capturou as imagens do participante no lado direito e a tela do PDA no lado esquerdo. Assim, foi possível observar e registrar as reações do participante, juntamente com sua locução. Os pesquisadores observaram o processo e anotaram os fatos interessantes. Procurou-se interagir adequadamente com $o$ participante, neste momento para não influenciar a sua performance nas tarefas.

Durante a realização das tarefas, aos usuários foi facultada a opção de parar para fazer suas críticas e registrar comentários e sugestões.

Ao término de cada tarefa, desligava-se a câmera e o arquivo era salvo. Após o término de todas as tarefas, o participante respondia um questionário pós-teste composto por onze perguntas fechadas e três perguntas abertas, onde podia sinalizar as suas facilidades e as suas dificuldades. Com base nestas respostas, os pesquisadores realizavam uma entrevista aberta, gravada em áudio, dando a possibilidade ao usuário de explicar mais profundamente as suas colocações neste questionário.

Ao final, era oferecido ao participante um pequeno presente por sua colaboração. A média de duração do processo inteiro costumava ser de uma hora e meia.

Em cada sessão estavam presentes o participante e dois pesquisadores observando, registrando problemas, comentários e comportamentos. Os pesquisadores ficavam posicionados junto ao participante, um de cada lado. Algumas sessões tiveram a participação de um convidado, membro da equipe de desenvolvimento do aplicativo.

\subsection{Análise dos Resultados dos Testes de Usabilidade}

Foi utilizada a abordagem top-down a partir das heurísticas de Nielsen [Nielsen 2005], que descrevem uma interface com boa usabilidade. Ao mesmo tempo, os pesquisadores realizaram uma inspeção heurística com base na revisão das 48 gravações dos testes, efetivando um registro detalhado dos problemas identificados.

Os testes de usabilidade foram úteis na detecção dos problemas recorrentes na leitura dos textos e puderam fornecer evidências sobre o impacto do instrumento nos entrevistadores. Nesses testes, os entrevistadores foram estimulados a "pensar em voz alta" (think aloud protocol) [Rubin \& Chrisnell 2008], portanto puderam expor melhor seus problemas e até sugerir soluções para resolvê-los. Os entrevistadores apresentaram dificuldades ao tentar executar suas tarefas diárias, como a leitura de perguntas, seguir instruções na tela, usar algumas funções do software ou sentiram falta de outras funções.

Algumas soluções propostas nos testes de usabilidade do aplicativo construído para o PDA foram implementadas. Para conferir se as implementações realizadas foram satisfatórias e reconhecer possíveis novas necessidades do usuário, foi solicitada uma nova fase de testes. A intenção de realizar diversos ciclos de testes com os resultados de testes de ciclos anteriores é identificar e refinar a qualidade das interações, para construir novas versões a fim de garantir que o sistema responda cada vez melhor às expectativas e necessidades dos usuários em suas tarefas. 


\section{Recomendações de Usabilidade para PDAs Utilizados em Entrevistas Pessoais para Pesquisas Domiciliares}

A análise dos resultados contribuiu para a compilação de todos os dados recolhidos com as observações no contexto de uso (seção 6), os testes de usabilidade em laboratório (seção 7) e as entrevistas em áudio e vídeo.

As imagens dos 48 vídeos gerados com as interações dos entrevistadores com o PDA foram analisadas e foram detectados 142 problemas de usabilidade, com repetição das ocorrências. Os resultados obtidos com as observações propiciaram uma visão detalhada dos problemas encontrados nos acompanhamentos de campo e nos testes de usabilidade e foram publicados em alguns textos de comunicação científica [Tavares, Agner \& Leal Ferreira 2010] [Agner, Tavares \& Leal Ferreira 2011].

Assim, foi possível identificar que a interface dos questionários apresentados em PDAs deve ser desenvolvida e planejada em conjunto por dois profissionais: os projetistas do questionário e o projetista da interface do sistema de coleta dos dados.

Com base nesses resultados, esta seção expõe recomendações de usabilidade para o desenvolvimento de sistemas de coleta de dados utilizados em PDAs. Dessa forma, foram criados dois grupos de recomendações: o primeiro, destinado aos projetistas dos questionários, mostra os cuidados ao elaborar as perguntas, respostas, conceitos e instruções, tendo em vista que serão apresentados em uma tela pequena de um computador de mão, quase sempre com os entrevistadores em pé e sob pressão de tempo; o segundo grupo destina-se a apoiar os projetistas de interfaces de sistemas de coleta de dados que utilizam os computadores de mão, sugerindo como a tecnologia pode acelerar o processo de entrevista e facilitar o trabalho dos entrevistadores.

As recomendações são consolidadas em duas tabelas (Tabelas 1 e 2) com o objetivo de compor um "Guia Rápido" para os profissionais envolvidos na elaboração dos questionários eletrônicos.

\section{Tabela 1. Recomendações para o Projetista de Questionários para Coleta de Dados.}

\begin{tabular}{|l|}
\hline Elaborar textos simples e curtos para perguntas, opções de respostas e instruções \\
\hline Evitar elaborar questões com excesso de opções de resposta \\
\hline Manter equilíbrio entre o tamanho da pergunta e a quantidade de opções de resposta \\
\hline $\begin{array}{l}\text { Preparar resumos explicativos sobre os conceitos de cada pergunta para serem } \\
\text { apresentados na tela }\end{array}$ \\
$\begin{array}{l}\text { Elaborar um pequeno texto sobre os objetivos da pesquisa e os benefícios de seus } \\
\text { resultados }\end{array}$ \\
\hline Evitar o uso de códigos ou termos técnicos nos textos \\
\hline Apresentar perguntas personalizadas, referenciando o nome do morador \\
\hline $\begin{array}{l}\text { Verificar a ordem de apresentação das perguntas para minimizar o tempo da entrevista, } \\
\text { suprimindo algumas perguntas do questionário eletrônico }\end{array}$ \\
Minimizar a quantidade de mensagens de alerta entre as perguntas \\
\hline
\end{tabular}


Tabela 2. Recomendações para o Projetista de Interfaces para Sistemas de Coleta de Dados.

\begin{tabular}{|l|}
\hline Sobre a aparência \\
\hline $\begin{array}{l}\text { Minimizar a carga cognitiva do entrevistador ao interpretar a tela, apresentando somente } \\
\text { as instruções que ele realmente necessita para realizar a entrevista. }\end{array}$ \\
\hline Utilizar feedbacks para o entrevistador acompanhar a evolução da entrevista \\
\hline Desenvolver ícones visualmente bem definidos \\
\hline $\begin{array}{l}\text { Certificar-se de que as combinações de cores de fundo e a cor do texto fornecem um } \\
\text { contraste suficiente }\end{array}$ \\
\hline Organizar adequadamente os rótulos dos menus de funcionalidades \\
\hline Certificar-se de que o questionário está consistente e padronizado \\
\hline Programar o dimensionamento automático do conteúdo da tela \\
\hline Sobre a pesquisa \\
\hline $\begin{array}{l}\text { Disponibilizar uma opção no sistema para explicar os conceitos da pergunta que está } \\
\text { sendo exibida na tela }\end{array}$ \\
\hline $\begin{array}{l}\text { Disponibilizar uma opção no sistema para explicar o motivo da pesquisa e informações } \\
\text { sobre os resultados }\end{array}$ \\
\hline Disponibilizar informações sobre a instituição e sobre o entrevistador \\
\hline Sobre a navegação entre as perguntas \\
\hline $\begin{array}{l}\text { Disponibilizar botões de navegação grandes entre as perguntas e manter distância } \\
\text { adequada entre eles }\end{array}$ \\
\hline $\begin{array}{l}\text { Manter visível uma opção para visualizar as perguntas e as respostas que já foram } \\
\text { incluídas no sistema }\end{array}$ \\
\hline Permitir o acesso rápido às perguntas já respondidas pelo informante \\
\hline Sobre a edição das respostas \\
\hline $\begin{array}{l}\text { Facilitar a edição de perguntas abertas, disponibilizando teclas para inserir ou apagar } \\
\text { qualquer parte do texto ou o texto inteiro. }\end{array}$ \\
\hline $\begin{array}{l}\text { Para questões com diversas opções de respostas, utilizar o recurso de "sugestão de } \\
\text { busca". }\end{array}$ \\
\hline $\begin{array}{l}\text { Prevenir erros do entrevistador durante a entrada de dados, como apresentar o teclado } \\
\text { numérico nas respostas onde só são aceitos números, por exemplo. }\end{array}$ \\
\hline $\begin{array}{l}\text { Analisar o componente utilizado para o registro de perguntas fechadas: considerar o } \\
\text { espaço na tela e a quantidade de itens de resposta }\end{array}$ \\
\hline Sobre a ajuda \\
problemas que ocorram \\
\hline Construir mensagens que estimulem o uso do sistema \\
\hline Traduzir todos os códigos \\
\hline
\end{tabular}


Tabela 2. Recomendações para o Projetista de Interfaces para Sistemas de Coleta de Dados.

\begin{tabular}{|l|}
\hline Sobre a tecnologia \\
\hline $\begin{array}{l}\text { Aproveitar a tecnologia disponível para a realização de cálculos e preenchimentos } \\
\text { automáticos }\end{array}$ \\
\hline Reduzir o tempo de resposta do sistema \\
\hline $\begin{array}{l}\text { Analisar o benefício do uso das tecnologias presentes nos dispositivos (GPS, mapas) e } \\
\text { verificar se sua implementação poderá causar atrasos ou dificuldades na entrevista. }\end{array}$ \\
\hline Disponibilizar e facilitar a opção de backup \\
\hline
\end{tabular}

A leitura e a compreensão dos textos elaborados pelos projetistas dos questionários provocaram problemas de usabilidade no sistema. A informação apresentada na tela do dispositivo móvel foi o motivo das divergências; estes resultados foram apresentados para a equipe de projetistas do questionário e algumas perguntas foram reformuladas. Sendo assim, as recomendações apresentadas nas tabelas 1 e 2 são complementares e mostram que a interface dos questionários apresentados em PDAs deve ser desenvolvida e planejada em conjunto por dois profissionais: os projetistas do questionário e o projetista da interface do sistema de coleta dos dados.

\section{Considerações Finais}

Como grande benefício de coletar dados com computadores, a tecnologia pode disponibilizar questionários sofisticados com funcionalidades especiais, especialmente em computadores de mão, conhecidos por PDAs. Entretanto, a interface de questionários disponibilizados nestes dispositivos pode apresentar alguns problemas de usabilidade.

A presente pesquisa teve como foco avaliar as dificuldades de uso que os entrevistadores enfrentam na realização de entrevistas pessoais empregando PDAs ao coletar dados para pesquisas estatísticas domiciliares. Foram realizadas observações em contexto de uso e duas fases de testes de usabilidade [Tavares, Agner \& Leal Ferreira 2010] [Agner, Tavares \& Leal Ferreira 2011] com a participação de entrevistadores do Instituto Brasileiro de Geografia e Estatística (IBGE). As observações em contexto de uso consistiram em acompanhar entrevistadores em visitas aos domicílios para realizar entrevistas pessoais e os testes de usabilidade envolveram observações e gravações de vídeos das interações dos entrevistadores, com o apoio de um laboratório portátil. Em todas as etapas foram coletados depoimentos, fotos e vídeos dos entrevistadores para complemento dos trabalhos realizados.

Problemas na interface como contraste de cores, tempo de resposta e a dificuldades para retornar às perguntas anteriores foram os mais evidentes durante a observação. Embora a pesquisa tenha se focado na parte tecnológica (hardware e software) da coleta de dados, percebeu-se que a concepção dos textos e das instruções dos questionários também trazia problemas de usabilidade. A tela reduzida dos dispositivos foi um dos causadores dos problemas de leitura de textos longos; problemas de interpretação, tanto por parte do entrevistador quanto pelos informantes foram observados quando as perguntas e as respostas eram longas ou complexas. 
A partir da análise dos resultados foi possível identificar dois perfis de profissionais influentes na construção dos questionários eletrônicos para PDAs: o projetista do questionário, indivíduo que faz parte de uma comissão técnica formada para elaborar o conteúdo do questionário [IBGE 2010] e o projetista da interface (desenvolvedores do sistema ou designers) do sistema de coleta dos dados. Seus produtos têm influência direta na usabilidade da aplicação, portanto, para cada perfil foi criado um grupo de recomendações de usabilidade, que foram apresentadas nas tabelas 1 e 2 .

As recomendações propostas, que expõem a realidade de campo, auxiliam a projetar instrumentos bem concebidos para ajudar os entrevistadores a realizar corretamente seu trabalho, evitando entrevistas mais difíceis e demoradas, ou forçandoos a atalhos que comprometam a consistência dos dados.

O método foi considerado satisfatório, pois foi proposto a partir da flexibilização dos testes tradicionais de usabilidade, de modo que pudessem ser adaptados ao contexto específico do Instituto Brasileiro de Geografia e Estatística (IBGE). Envolveu testes de usabilidade de custo baixo, o que permite que ele seja contextualizado e aplicado em outros cenários, como avaliação de websites, intranets, processos automatizados, ambientes de educação à distância e demais métodos de coleta eletrônica de dados, como questionários elaborados para pesquisas online (Web Surveys).

Como trabalho futuro, sugere-se a aplicação das recomendações que foram propostas neste artigo. Um experimento de campo pode avaliar os resultados entre os dados coletados sem as recomendações e os dados coletados com as recomendações, para uma comparação do tempo de coleta e de seu efeito na qualidade das respostas. Para cada pergunta, pode ser medido o tempo gasto para a obtenção da resposta, a fim de verificar quais perguntas geram atrasos na coleta de dados. A sequência de teclas que foram utilizadas nas respostas pode ser armazenada para fornecer uma indicação das dificuldades do entrevistador com o PDA. Essas informações podem ser particularmente úteis para analisar a eficácia das recomendações e refiná-las de acordo com as necessidades impostas pelo experimento, até alcançar um padrão ideal de coleta de dados.

TAVARES, P. Z.; LEAL FERREIRA, S. B.; AGNeR, L.; CAPRA, E. P.

A Influência de Ambientes de Uso Adversos na Coleta de Dados Estatísticos Utilizando Dispositivos Móveis iSys - Revista Brasileira de Sistemas de Informação, Rio de Janeiro, vol. 7, No. 1, p. 66-88, 2014. 


\section{Referências}

Agner, L.; Tavares, P.; Leal Ferreira, S. B. (2011). "Scenario and Task Based Interview to Evaluate Usability of Computer Assisted Data Collection". A. Marcus (Ed.): Design, User Experience, and Usability, Pt II, HCII 2011, LNCS 6770, pp. 349-358, 2011. Springer-Verlag Berlin Heidelberg 2011.

Childs, J. H.; Landreth, A. (2006). "Analyzing Interviewer/Respondent Interactions while Using a Mobile Computer-Assisted Personal Interview". Field Methods, Vol. 18, No. 3. (Agosto 2006), pp. 335-351. http://fmx.sagepub.com/content/18/3/ 335. Acesso em: 01/07/2010.

Couper, M. P. (1994). “Discussion: What Can CAI Learn from HCI?" In: Proceedings of the Seminar on New Directions in Statistical Methodology. pp. 363-377 Washington: Statistical Policy Office, Office of Management and Budget. http://www.fcsm.gov/working-papers/SPWP23b_session7.pdf. Acesso em: $15 / 05 / 2011$.

Couper, M. P.; Nicholls, W. L. II. (1998). "The history and development of CASIC". In: M. P. Couper, R. P. Baker, J. Bethlehem, C. Z. F. Clark, J. Martin, W. L. Nicholls II, \& J. M. O'Reilly (Eds.). Computer Assisted Survey Information Collection. New York: Wiley.

Gravlee, C. C. et al. (2006). "Handheld Computers for Direct Observation of the Social and Physical Environment". Field Methods, 2006. http://fmx.sagepub.com/ content/18/4/382. Acesso em: 02/10/2010.

Hanses, S. E.; Couper, M. P.; Fuchs, M. (1998). "Usability Evaluation of the NHIS CAPI Instrument". Survey Research Center, University of Michigan \& Catholic University of Eichstaett, Germany. 1998

IBGE. (2010). Revista Vou te Contar - A Revista do Censo. Número 14, jan/fev 2010. http://www.censo2010.ibge.gov.br/download/revista/vtc14_web.pdf. Acesso em: 05/07/2010.

Jäckle, A. et al. (2013). The Effect of Interviewer Experience, Attitudes, Personality and Skills on Respondent Co-operation with Face-to-Face Surveys. Survey Research Methods. Vol.7, No.1, pp. 1-15 ISSN 1864-3361. https://ojs.ub.uni-konstanz.de/ srm/article/view/4736. Acesso em: 08/04/2014.

Leal Ferreira, S. B.; Nunes, R. R. (2008). e-Usabilidade, Rio de Janeiro, LTC.- 2008

Lepkowski, J.M. et al. (1998). "CAPI Instruments Evaluation: Behavior Coding, Trace Files and Usability Methods". In: Proceedings of the Section on Survey Research Methods, American Statistical Association. 917-922. 1998. http://www.amstat.org/ sections/srms/proceedings/papers/1998_158.pdf. Acesso em: 11/1/2011.

Loosveldt, G.; Beullens, K. (2013). 'How long will it take?' An analysis of interview length in the fifth round of the European Social Survey. Survey Research Methods. Vol.7, No.2, pp. 69-78. ISSN 1864-3361. http://www.surveymethods.org. Acesso em: 07/04/2014. 
Martin, E. et al. (2007). Guidelines for Designing Questionnaires for Administration in Different Modes. Jun, 2007. U.S. Census Bureau: Washington, DC. 120 pages. www.census.gov/srd/mode-guidelines.pdf. Acesso em: 20/10/ 2010.

Nielsen, J. (2005). Ten usability heuristics. http://www.nngroup.com/articles/tenusability-heuristics. Acesso em: 20/08/2014.

Nielsen, J.; Budiu, R. (2012). Mobile Usability. New Riders. $1^{a}$ edição. 216 p.

Rubin, J.;. Chrisnell, D. (2008) Handbook of usability testing: How to plan, design and conduct effective tests. Indianapolis, IN; Wiley Publishing, Inc.

Tavares, P.; Agner, L.; Leal Ferreira, S. B. (2010). "Avaliação de Usabilidade de Dispositivos Móveis de Coleta de Dados Domiciliares Através de Entrevistas Baseadas em Cenários e Tarefas". In: IX Simpósio de Fatores Humanos em Sistemas Computacionais, IHC, 2010, Belo Horizonte. 